\title{
Fatigue in Fiber-Metal Laminates for Small Wind Turbine Blades Application
}

\author{
Wei Sai ${ }^{1, *}$, Gin Boay Chai $^{1}$ \\ ${ }^{1}$ Energy Research Institute (ERI@N), Nanyang Technological University, 50 Nanyang Drive, Singapore 639798 \\ ${ }^{2}$ Mechanical and Aerospace Engineering School, Nanyang Technological University, 50 Nanyang Drive, Singapore 639798
}

\begin{abstract}
A methodology to study the fatigue of a wind turbine blade in a $10 \mathrm{KW}$ small wind turbine is proposed in this paper. Two working conditions (namely normal fatigue operation condition and extreme wind condition) are considered based on IEC61400-2. The maximum load calculated from both cases were used as a reference to perform material sample fatigue study. Fiber-metal laminate - GLARE 3/2 with a centre $1 \mathrm{~mm}$ notch on the external aluminium layers was modelled based on fracture mechanics approach to calculate the stress intensity factor and fatigue crack growth rate at maximum applied stress of 240Mpa. GLARE panel fabrication and tensile tests were included. The fatigue tests were performed on unnotched samples with stress range from $80 \mathrm{Mpa}$ to $300 \mathrm{Mpa}$ and plotted into S-N curve.
\end{abstract}

\section{Introduction}

To estimate the fatigue life of wind blades in the natural environment, local wind load history is needed. This load history is based on the local wind history and the load induced on the wind blade. The load-time history data requires further processing using rain flow to count the peaks and valleys. The processed data is plotted into histogram that displays the stress range versus its frequency. The stress range would be tested through fatigue tests or modeled and plot into S-N curve. WISPER and WISPERX are specially developed spectrum loading sequence based on the actual windload data captured in Europe $[1,2]$ to simulate or do the testing of wind blades. To estimate the fatigue life of wind blades at specific load ranges, either structural level models or sample tests are to be done.

The load calculation performed in this paper is based on a simplified average wind speed of $8.5 \mathrm{~m} / \mathrm{s}$ for a $10 \mathrm{KW}$ small wind turbine with blade diameter $6 \mathrm{~m}$. The induced moment and stress at blade root section based on standard for small wind turbine IEC61400-2[3]. The load calculated for the wind blade root section was taken as reference for the sample modeling and testing. The fatigue analysis was performed on fiber-metal laminate (GLARE) samples for a stress range from 80Mpa to 300Mpa.

Currently the choices of wind blade materials are glass fiber composite, carbon fiber composite, wood, steel and aluminum alloy[4]. Glass fiber composites and carbon fiber composites are the most commonly used for wind blade materials and lots of fatigue studies have been done on fiber reinforced composites[5-7].

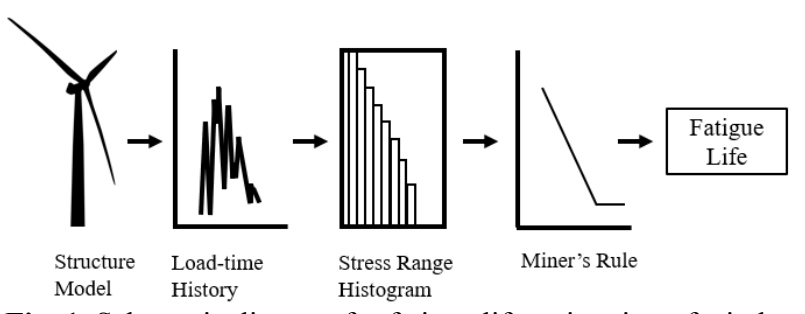

Fig. 1. Schematic diagram for fatigue life estimation of wind blades.

The designed working life for wind turbine is normally $20-25$ years. Fatigue tests and fatigue modeling on fiber reinforced composites for wind blades are normally up to a few million cycles. A typical fibermetal laminate such as GLARE was developed about thirty years ago and successfully applied in the fuselage skin for Airbus 380[8] due to its low specific weight and high fatigue strength compared with pure alloy materials[9]. The main reason of the high fatigue probability for GLARE is the fiber bridging effect to restraint the crack tip opening at the aluminum layers to reduce the stress intensity factor and decrease the crack growth rate[10]. In contrast to commercial aircraft application, wind turbine blades require higher fatigue cycle since the required working life is longer due to the vibration induced by environment (mainly wind). Up until now, GLARE has yet to be applied to the wind turbine blades. Fatigue modeling based on fracture mechanics and tension-tension fatigue tests were performed based on the highest extreme load calculated at the small wind blade root section.

\footnotetext{
Corresponding author: mgbchai@ntu.edu.sg
} 




Fig. 2. Schematic S-N plot for various fatigue critical application[11].

\section{Fatigue Model}

The fatigue model applied is based on Paris' law for monilithic metals. Assumptions have been made that the fatigue data of aluminum 2024 could be applied for GLARE laminate fatigue life[12, 13]. To estimate the number of fatigue cycles, effective stress intensity factor is required which require the stress level in the aluminum layer to be calculated first.

\subsection{Wind blade load calculation}

A $10 \mathrm{KW}$ small wind turbine blade fatigue loading under normal operation and ultimate load under extreme wind loading are calculated based on IEC61400-2[5]. The basic design parameters are taken from Windlite $10 \mathrm{KW}$ DC wind turbine. The loads and stresses are calculated at blade root section where the highest bending moment is found. An average wind speed of $8.5 \mathrm{~m} / \mathrm{s}$ with tip speed ratio of 4.68 is applied in the load calculation. The radial distance between the center of gravity of the blade and the rotor center is estimated by assuming trapezoid shape plane cross-section with blade root air foil NREL S822 and tip air foil NREL S823. The formula involved in the calculation in Table 2 could be found in IEC61400-2, and the related design parameters are shown in Table 1.

Table 1. Design parameters for $10 \mathrm{KW}$ wind turbine

\begin{tabular}{|c|l|l|}
\hline$R$ & Rotor radius & $3 \mathrm{~m}$ \\
\hline $\mathrm{n}_{\text {design }}$ & Rotor speed at rated wind speed & $130 \mathrm{rpm}$ \\
\hline $\mathrm{n}_{\text {max }}$ & Max rotational speed & $260 \mathrm{rpm}$ \\
\hline$V_{\text {design }}$ & Designed wind speed & $8.4 \mathrm{~m} / \mathrm{s}$ \\
\hline$P_{\text {design }}$ & Designed electrical power & $10 \mathrm{Kw}$ \\
\hline$Q_{\text {design }}$ & Designed shaft torque & $918 \mathrm{Nm}$ \\
\hline$\eta$ & Efficiency (assumed) & 0.8 \\
\hline$m_{B}$ & One blade mass & $25 \mathrm{Kg}$ \\
\hline
\end{tabular}

\begin{tabular}{|c|l|l|}
\hline $\mathrm{R}_{\mathrm{cog}}$ & $\begin{array}{l}\text { The radial distance between the } \\
\text { center of gravity of a blade and the } \\
\text { rotor center }\end{array}$ & $1.5 \mathrm{~m}$ \\
\hline $\mathrm{B}$ & Number of blades & 3 \\
\hline$\lambda_{\text {design }}$ & Designed tip speed ratio & 4.86 \\
\hline $\mathrm{C}_{\mathrm{d}}$ & Drag coefficient & 1.5 \\
\hline $\mathrm{C}_{\mathrm{I}, \mathrm{max}}$ & Max lift coefficient & 2 \\
\hline $\mathrm{V}_{\mathrm{e} 50}$ & $\begin{array}{l}\text { Small wind turbine class IV } \\
\text { maximum gust }\end{array}$ & $42 \mathrm{~m} / \mathrm{s}$ \\
\hline $\mathrm{A}_{\mathrm{proj}, \mathrm{B}}$ & $\begin{array}{l}\text { Blade section area projected on to a } \\
\text { plane perpendicular to wind direction }\end{array}$ & $1.05 \mathrm{~m}^{2}$ \\
\hline
\end{tabular}

The loads in the normal operation is considered as fatigue load caused by constant amplitude cyclic loading at blade root section. The loads at the extreme wind loading condition are the ultimate loads when wind blade is still functioning. Loads from both cases are taken as reference for the following crack growth rate modelling and fatigue tests.

Table 2. Wind blade load calculation

\begin{tabular}{|l|l|l|l|}
\hline \multicolumn{4}{|l|}{ Normal operation } \\
\hline Centrifugal load & 13900 & $\mathrm{~N}$ & $\Delta \mathrm{F}_{\mathrm{ZB}}$ \\
\hline Edgewise bending & 1041 & $\mathrm{Nm}$ & $\Delta \mathrm{M}_{\mathrm{XB}}$ \\
\hline Flapwise bending & 1488 & $\mathrm{Nm}$ & $\Delta \mathrm{M}_{\mathrm{YB}}$ \\
\hline Axial loading stress & 7.08 & $\mathrm{Mpa}$ & $\sigma_{\mathrm{ZB}}$ \\
\hline Bending stress & 148 & $\mathrm{Mpa}$ & $\sigma_{\mathrm{MB}}$ \\
\hline $\begin{array}{l}\text { Combined load } \\
\text { Extreme wind loading }\end{array}$ & 155 & $\mathrm{Mpa}$ & $\sigma_{\mathrm{eq}}$ \\
\hline $\begin{array}{l}\text { Edgewise bending } \\
\text { Elapwise bending } \\
\text { (parked rotor) }\end{array}$ & 1041 & $\mathrm{Nm}$ & $\Delta \mathrm{M}_{\mathrm{XB}}$ \\
\hline $\begin{array}{l}\text { Flapwise bending } \\
\text { (spinning rotor) }\end{array}$ & 2278 & $\mathrm{Mpa}$ & $\Delta \mathrm{M}_{\mathrm{YB}}$ \\
\hline $\begin{array}{l}\text { Axial loading stress } \\
\text { (spinning rotor) }\end{array}$ & 7.08 & $\mathrm{Mpa}$ & $\sigma_{\mathrm{ZB}}$ \\
\hline $\begin{array}{l}\text { Bending stress } \\
\text { (parked rotor) }\end{array}$ & 225 & $\mathrm{Mpa}$ & $\sigma_{\mathrm{MB}}$ \\
\hline $\begin{array}{l}\text { (spinning rotor) } \\
\text { Combined load }\end{array}$ & 204 & $\mathrm{Mpa}$ & $\sigma_{\mathrm{MB}}$ \\
\hline $\mathrm{M}_{\mathrm{YB}}$ \\
\hline Nombined load
\end{tabular}




\subsection{Stress in Al layers}

The stress level in aluminum layer is calculated based on classical laminate theory. The governing equation is shown in equation (1), and the detail procedure could be found from Ref[10]. The stress in aluminum layer is composed of internal stress due to applied stress to the laminate and the tensile curing stress due to the different thermal expansion coefficient [14].

$$
\sigma_{\mathrm{Al}}=\mathrm{S}_{\mathrm{Al}}\left[\mathrm{S}_{\text {lam }}^{-1}\left(\sigma_{\text {lam }}\right)+\Delta \mathrm{T}\left(\alpha_{\text {lam }}-\alpha_{\mathrm{Al}}\right)\right]
$$

The maximum load calculated from the wind blade root section is $233 \mathrm{Mpa}$. The stress of $240 \mathrm{Mpa}$ was applied in the following stress calculation in aluminum layers as well as the stress intensity factor and fatigue crack growth rate calculation.

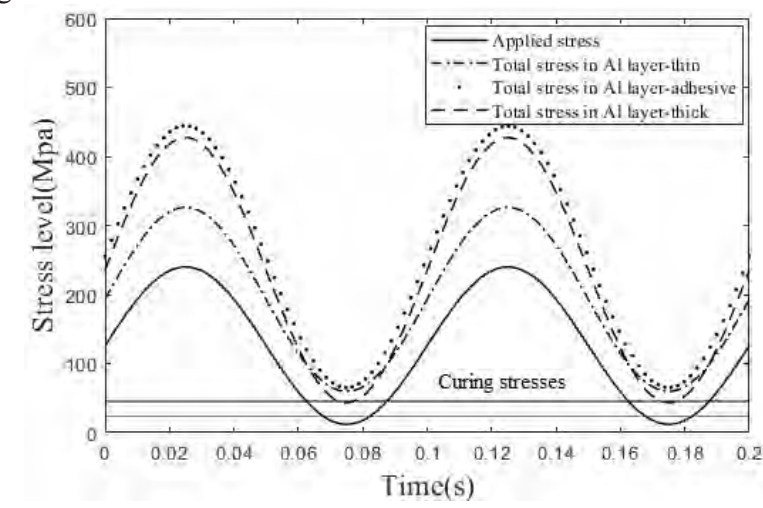

Fig. 3. Stress calculated in an aluminum layer with applied stress $240 \mathrm{Mpa}$ and stress ratio $\mathrm{R}=0.05$.

Three different types of modeling are studied regarding the calculation of stress in the aluminum layer:

The total stress in Al layer (adhesive model) considering the adhesive layers applied at metal and prepreg interface as one separate layer and the adhesive properties are taken from[13].

The total stress in Al layer (thin model)- considering the adhesive layers of negligible thickness and merging it with the prepreg layers which means the thickness of laminate panel less than the actual panel thickness.

The total stress in Al layer (thick model) - assuming the adhesive is cured into prepreg layer and the thickness of the adhesive is averaged and added for each prepreg layer which reflects the actual panel thickness.

As the thickness of prepreg increases, the internal stress due to the externally applied load in the prepreg layers and aluminum layers also increases. As a result, the total stress level in the individual aluminum layer is higher as it accounts for the extra adhesive layers or thicker prepreg layers due to the merger with extra adhesive layers. For the rest of the modelling, the "total stress in Al layer (thin model) is applied.

\subsection{Bridging stress}

The bridging stress is defined as the stress pulled up the cracked metal layers in fiber-metal laminates by the intact fibers and prevent the cracks further opening. The bridging stress controls the crack growth rate, and it is a prerequisite to calculate the laminate crack growth rate. One of the approaches to calculating the bridging stress is the model proposed in [15] and further improved in [12].

The governing equation is shown below based on the GLARE laminate crack opening displacement caused by applied stress and compensate partially by the fiber bridging stress which equals to the fiber elongation and prepreg deformation along the loading direction. The illustration of the crack opening displacement with elliptical delamination in shown in Figure 4.



Fig. 4. Crack opening geometry with half crack length a divided into $\mathrm{N}$ bar elements[15].

$$
\mathrm{u}_{\infty}(\mathrm{x})-\mathrm{u}_{\mathrm{br}}(\mathrm{x})=\delta_{\mathrm{f}}(\mathrm{x})+\delta_{\mathrm{pp}}(\mathrm{x})
$$

The governing equation could be further transformed into the equation below:

$$
\begin{gathered}
\sigma_{b r}=H^{-1} Q \\
H=\sum_{j=1}^{N} \frac{u\left(x_{i}, x_{j}\right)}{\sigma_{b r}\left(x_{j}\right)}-\frac{b(i)}{E_{f}} \delta(i, j) \\
Q=v_{a p}(x)-\delta_{p p}(i)-\frac{s_{f}}{E_{f}} b(i)
\end{gathered}
$$

And $\sigma_{\mathrm{br}}$ represent the bridging stress in the composite; $\mathrm{u}\left(\mathrm{x}_{\mathrm{i}}, \mathrm{x}_{\mathrm{j}}\right)$ is the crack opening displacement; $b(\mathrm{i})$ is the delamination shape function; and $\delta(\mathrm{i}, \mathrm{j})$ is Kronecker.

To calculate the bridging stress, 60 bar elements are used, and matrix operation is used to solve the equation. The function of Kronecker is like an identity matrix, and it forms a square matrix with the same dimension as the first term in the equation of " $H$ ".

Based on the model in [12], the bridging stress in GLARE $3 / 2$ with glass fiber prepreg layup $\left[0^{\circ}\right]_{4}$ was calculated. The triangular and elliptical shapes were assumed for delamination due to the notch on the external aluminum layers. Different delamination shape functions could be found in $[12,15]$. The half crack size is modelled at $12.5 \mathrm{~mm}$ and half delamination size at $5 \mathrm{~mm}$ with a center notch size $1 \mathrm{~mm}$. The applied stress to the composite sample is $240 \mathrm{Mpa}$ with stress ratio $\mathrm{R}=0.05$. The results are shown in Figure 5 . 


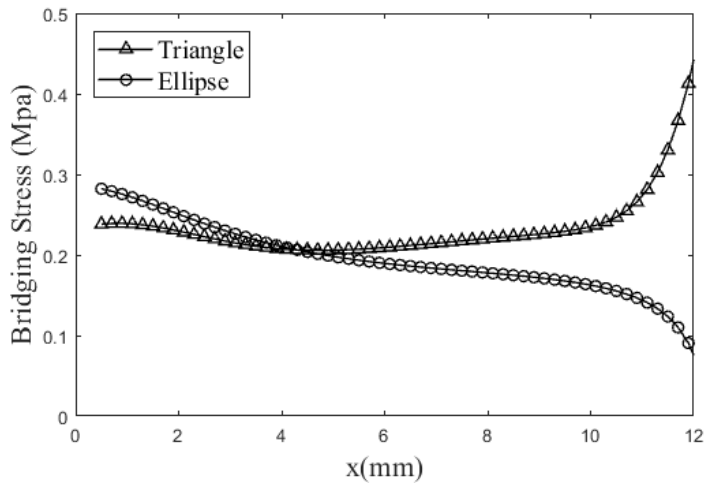

Fig. 5. Bridging stress for GLARE 3/2-[0 $\left[0^{\circ}\right]_{4}-0.4$ with $\mathrm{a}=10 \mathrm{~mm}, \mathrm{~b}=5 \mathrm{~mm}$ and central notch radius $0.5 \mathrm{~mm}$.

\subsection{Stress intensity factor}

The effective stress intensity factor includes far-field stress intensity factor and the bridging stress intensity factor. The equation for center-cracked specimen is shown in [12].

$$
\begin{gathered}
\mathrm{K}_{\mathrm{far}}=\sigma_{\mathrm{Al}} \sqrt{\pi \mathrm{a}} \\
\mathrm{K}_{\mathrm{br}}=2 \sum_{\mathrm{i}}^{\mathrm{N}} \frac{\sigma_{\mathrm{br}, \mathrm{Al}}\left(\mathrm{x}_{\mathrm{i}}\right) \mathrm{w}}{\sqrt{\pi \mathrm{a}}} \frac{\mathrm{a}}{\sqrt{\mathrm{a}^{2}-\mathrm{x}_{\mathrm{i}}^{2}+\mathrm{b}_{\mathrm{i}}^{2}}}(1 \\
\left.+\frac{1}{2}(1+\mathrm{v}) \frac{\mathrm{b}_{\mathrm{i}}^{2}}{\mathrm{a}^{2}-\mathrm{x}_{\mathrm{i}}^{2}+\mathrm{b}_{\mathrm{i}}^{2}}\right)
\end{gathered}
$$

Where $\sigma_{\mathrm{Al}}$ is the stress level in aluminum layer which could be calculated based on classical laminate theory[10]; $\sigma_{\mathrm{br}, \mathrm{Al}}$ is the bridging stress in aluminum layer and it is calculated using the rule of the mixture; and $\mathrm{w}$ is the bar element width.

The bridging stress intensity factor could be calculated once the bridging stress is obtained from equation (3).

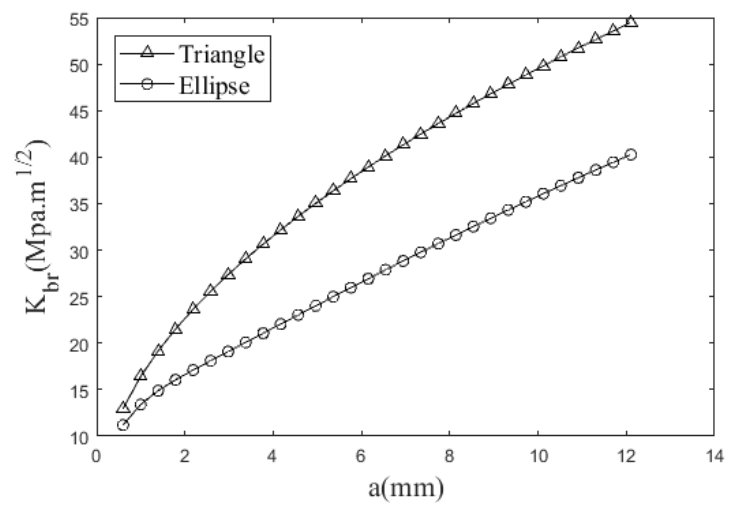

Fig. 6. Bridging stress intensity factor for applied stress $240 \mathrm{Mpa}$ and stress ratio $\mathrm{R}=0.05$.

\subsection{Fatigue crack growth rate}

The fatigue crack growth rate is modeled based on Paris' law. The model does not include the crack initiation for the metal layer since it is notched with a $1 \mathrm{~mm}$ cut in the center of the specimen. The unit for da/dN is $(\mathrm{m} / \mathrm{cycle})$.

$$
\begin{gathered}
\frac{\mathrm{da}}{\mathrm{dN}}=\mathrm{C} \Delta \mathrm{K}_{\mathrm{eff}}^{\mathrm{n}} \\
\Delta \mathrm{K}_{\mathrm{eff}}=\left(1-\mathrm{R}^{1.35}\right)\left(\mathrm{K}_{\mathrm{far}}+\mathrm{K}_{\mathrm{br}}\right)
\end{gathered}
$$

Where $\mathrm{C}=2.17 \times 10^{-12}$ and $\mathrm{n}=2.94$ are aluminum 2024-T3 material constants. Different value of $C$ and $n$ could also be found in [13]. Once the crack growth rate is calculated, the fatigue cycle $\mathrm{N}$ could be obtained by doing the integration of the equation (6).

The plot of fatigue crack growth rate is shown in Figure 6. The correction factor for the sample width geometries is shown in equation (8) below.

$$
\beta=\frac{1}{\sqrt{1-\left(\frac{2 \mathrm{a}}{\mathrm{W}}\right)^{2}}}
$$

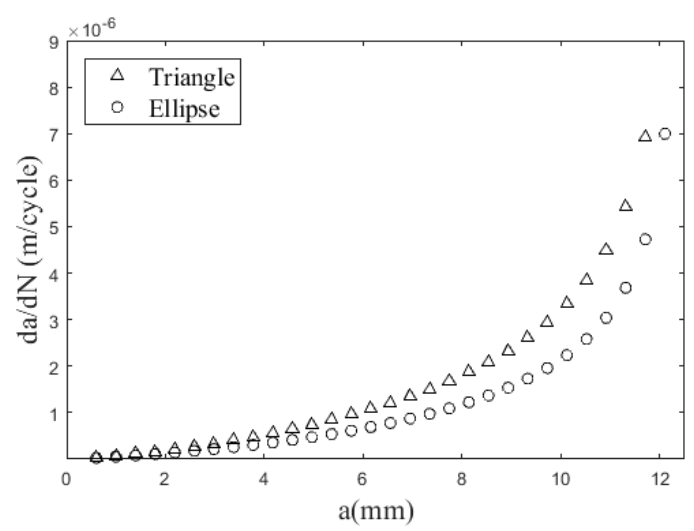

Fig. 7. The crack growth rate for GLARE $3 / 2-\left[0^{\circ}\right]_{4}-0.4$ with triangular and elliptical delamination shapes.

\section{Experimental data}

GLARE 3/2 panels were fabricated with aluminum 2024-T3 of thickness $0.3 \mathrm{~mm}$ and $0.4 \mathrm{~mm}$, and Hexcel 913 glass fiber prepreg with $\left[0^{\circ}\right]_{4}$ and $\left[0^{\circ} / 90^{\circ}\right]_{S}$ layup. Redux film adhesive was applied at the interface of aluminium layer and prepreg layer to promote the adhesion between metal and composite layer.

\subsection{Fabrication}

GLARE panels were fabricated at curing temperature of $120^{\circ} \mathrm{C}$ as shown in Figure 7 at pressure of $80 \mathrm{psi}$ and vacuum pressure of $-20 \mathrm{psi}$. The total autoclave cycle time is around 2-3 hours. The error percentage is controlled within $5 \%$ during the heat up and curing stages. 


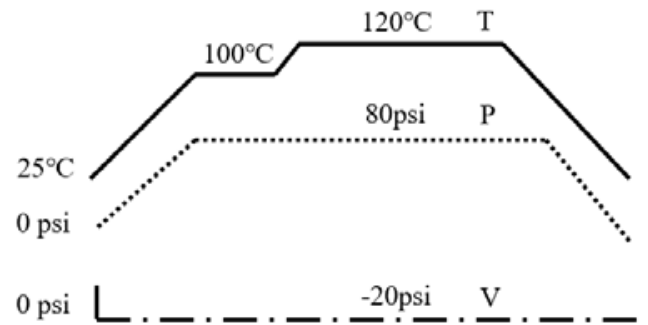

Fig. 8. GLARE panel curing cycle

The fabricated GLARE panel is shown in Figure 8. Part of the excess adhesive applied at the interface between aluminum layers and prepreg layers was cured and absorbed by the bleeder fabric.

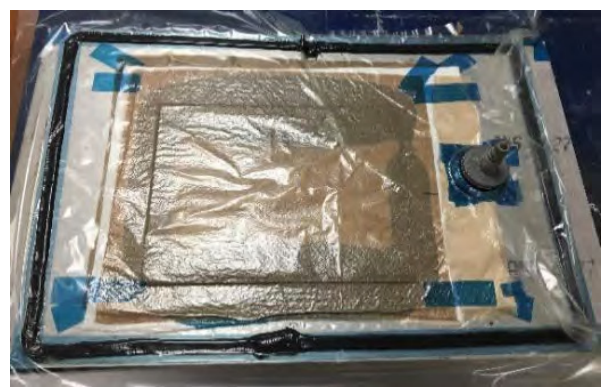

Fig. 9. GLARE $3 / 2-\left[0^{\circ} / 90^{\circ}\right]_{\mathrm{S}}-0.3$ was cured at $120^{\circ} \mathrm{C}$ with autoclave machine.

\subsection{Tensile test}

Tensile tests were performed based on standard ASTM D3039[16]. The sample size is $25 \mathrm{~mm}$ in width and $210 \mathrm{~mm}$ in length. Thickness is around $2-3 \mathrm{~mm}$. The test results for GLARE 3/2 with prepreg layup $\left[0^{\circ} / 90^{\circ}\right]_{\mathrm{S}}$ were compared for GLARE 3/2 with prepreg layup $\left[0^{\circ}\right]_{4}$. The GLARE samples with unidirectional fiber layup show $27.7 \%$ higher in ultimate tensile strength and $13.04 \%$ lower in yield strength. The stress-strain plot is shown in Figure 9.

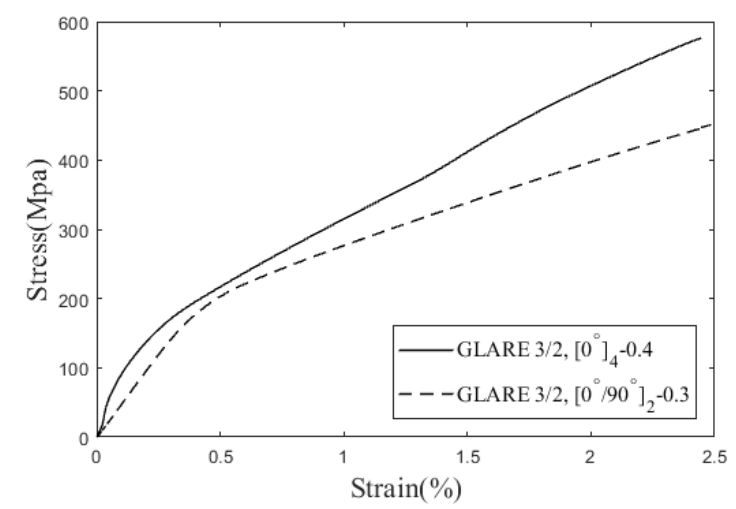

Fig. 10. Stress-strain results for GLARE panels.

\subsection{Fatigue test}

Tension-tension constant amplitude fatigue tests were performed using MTS 810 servo-hydraulic testing machine and based on ASTM D3479[17]. The maximum stress applied is from $80 \mathrm{Mpa}$ to $300 \mathrm{Mpa}$ at a stress ratio of $\mathrm{R}=0.05$ and frequency of $5 \mathrm{~Hz}$ on GLARE $3 / 2-\left[0^{\circ}\right]_{4}$ 0.4 samples. Fatigue test stopped when the samples are total fractured to the whole width. The sample tested at a maximum stress of $80 \mathrm{Mpa}$ showed a run-out at $10^{6}$ cycle and no cracks were found at the external aluminum layers.

To study the total fatigue life including the fatigue initiation and crack propagation for GLARE panels with unidirectional fiber layup, no predefined notches are made onto the samples.

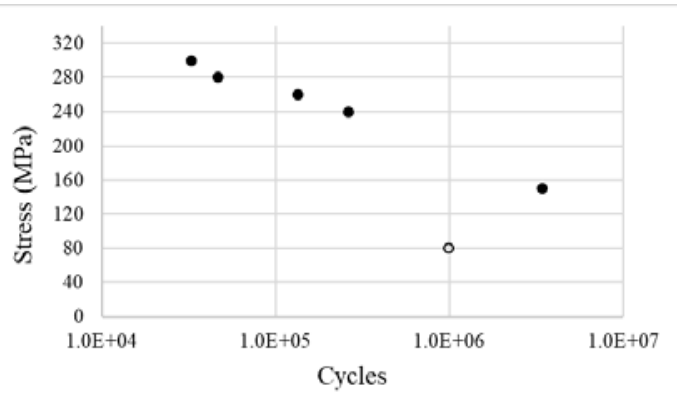

Fig. 11. S-N plot for GLARE $3 / 2-\left[0^{\circ}\right]_{4}-0.4$ samples

\section{Summary and conclusion}

The model applied for the calculation of the stress level in the aluminum layer was based on classical laminate theory. Three cases were proposed regarding the extra layers of adhesive applied at the metal to prepreg interfaces. The stress value used for the following calculation was the one without considering the extra adhesive layers.

The model for bridging stress was based on the assumption of the triangular and elliptical delamination shapes with a center notch on the specimen external aluminum layers. It's applicable only for center-cracked constant amplitude tension-tension fatigue test for unidirectional fiber layup.

The stress intensity factor and crack growth rate are positively related to the bridging stress, higher the bridging stress higher the crack growth rate. The material constant of $\mathrm{C}$ and $\mathrm{n}$ are assumed to be accurate although different value was used at other publications.

To study the fatigue life which includes fatigue initiation and crack propagation, the fatigue tests were performed on un-notched test specimens. The maximum stress applied was based on the maximum load calculated from the wind blade root section and the S-N curve showed quite good fatigue life.

Acknowledgements: This work was supported by the scholarship and fundings from Interdisciplinary Graduate School and Energy Research Institute(ERI@N)at Nanyang Technological University, Singapore. The laboratory and computation supports of the School of Mechanical and Aerospace Engineering is also much appreciated.

\section{References}

[1] A. Tenhave, "WISPER and WISPERX: Final definition of two standardised fatigue loading 
sequences for wind turbine blades," NASA STI/Recon Technical Report N, vol. 94, (1992)

[2] A. Ten Have, "WISPER: a standarized fatigue load sequence for HAWT-blades," Nationaal Lucht-en Ruimtevaartlaboratorium(1988)

[3] Wind Turbines - Part 2: Small wind turbines. IEC 61400-2:2013., (2013)

[4] E. Hau, Wind Turbines Fundamentals, Technologies, Application, Economics. (2013)

[5] A. Poursartip and P. W. R. Beaumont, "The fatigue damage mechanics of a carbon fibre composite laminate: II-life prediction," Compos. Sci. Technol., Article vol. 25, no. 4, pp. 283-299, (1986)

[6] J. Degrieck and W. Van Paepegem, "Fatigue damage modeling of fibre-reinforced composite materials: Review," Appl. Mech. Rev., Review vol. 54, no. 4, pp. 279-299, (2001)

[7] J. Degrieck and W. Van Paepegem, "Fatigue damage modeling of fibre-reinforced composite materials," Appl. Mech. Rev., vol. 54, no. 4, pp. 279-300, (2001)

[8] G. Wu and J.-M. Yang, "The mechanical behavior of GLARE laminates for aircraft structures," JOM, vol. 57, no. 1, pp. 72-79, (2005)

[9] G. B. Chai and P. Manikandan, "Low velocity impact response of fibre-metal laminates- $\mathrm{A}$ review," Compos. Struct., vol. 107, pp. 363-381, (2014)

[10] J. J. Homan, "Fatigue initiation in fibre metal laminates," Int. J. Fatigue, Article vol. 28, no. 4, pp. 366-374, (2006)

[11] H. Sutherland, "On the fatigue analysis of wind turbines, Sandia National Laboratories," SAND990089, Albuquerque, New Mexico, (1999)

[12] R. Alderliesten, "Analytical prediction model for fatigue crack propagation and delamination growth in Glare," Int. J. Fatigue, vol. 29, no. 4, pp. 628-646, (2007)

[13] P.-Y. Chang and J.-M. Yang, "Modeling of fatigue crack growth in notched fiber metal laminates," Int. J. Fatigue,, vol. 30, no. 12, pp. 2165-2174, (2008)

[14] T. Sinmazçelik, E. Avcu, M. T. Bora, and O. Çoban, "A review: Fibre metal laminates, background, bonding types and applied test methods," Mater. Des., Review vol. 32, no. 7, pp. 3671-3685, (2011)

[15] Y.-J. Guo and X.-R. Wu, "Bridging stress distribution in center-cracked fiber reinforced metal laminates: modeling and experiment," Eng. Fract. Mech., vol. 63, no. 2, pp. 147-163, (1999)

[16] A. C. D.-o. C. Materials, Standard test method for tensile properties of polymer matrix composite materials. ASTM International, (2008)

[17] I. De Baere, W. Van Paepegem, M. Quaresimin, and J. Degrieck, "On the tension-tension fatigue behaviour of a carbon reinforced thermoplastic part I: Limitations of the ASTM D3039/D3479 standard," Polym. Test., vol. 30, no. 6, pp. 625-632, (2011) 